\title{
The health fair model for surveillance of non-communicable disease: a pilot study in St. Kitts
}

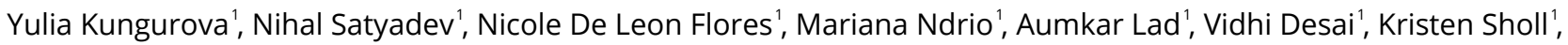
Ngoc Le', Elizabeth Benson', Raven Goodwin', Jesica Flint', Surpreet Kuhnkuhn', Agnes Beachman', Kenneth Alonso'

1 St. Kitts and Nevis Chronic Disease Evaluation and Management Research Group, University of Medicine and Health Science, Basseterre, St. Kitts, West Indies

Keywords: non-communicable disease, health surveillance, health fair model, west indies

https://doi.org/10.29392/001c.16685

\section{Journal of Global Health Reports}

Vol. 4, 2020

\begin{abstract}
Background
Non-communicable diseases (NCDs) are the leading cause of morbidity and mortality worldwide. An important first step to create programs of meaningful intervention and prevention is the surveillance of disease burden in the population to assess specific needs and to aid in resource allocation.
\end{abstract}

\section{Methods}

We employed the World Health Organization (WHO) STEPwise approach to Surveillance (STEPS) guidelines to investigate behavioral risks. Anthropometric data were collected. Biochemical analytes measured included glucose, cholesterol, and hemoglobin. Airway resistance and macular degeneration were also determined. Multivariate analysis followed by stepwise regression were performed both including and excluding cases with incomplete reporting.

\section{Results}

Of the 155 individuals ( $0.44 \%$ of the population) included in the pilot study, $30.7 \%$ of men and $28.2 \%$ of women were hypertensive, $33.3 \%$ of men and $31.9 \%$ of women were obese, $46.7 \%$ of men and $61.5 \%$ of women had elevated cholesterol. $3.6 \%$ of men and $3.7 \%$ of women were diabetic, $23.1 \%$ of men and $40.6 \%$ of women were anemic, $34.7 \%$ of 49 evaluable participants had increased airway resistance; and three participants with suspected macular degeneration. Of all participants, 37.5\% had elevated cholesterol and were not aware of it, $13.6 \%$ had hypertension and were not aware of it. Impaired glucose tolerance was found in $8.6 \%$ of patients. There was no correlation between hypertension, obesity, elevated glucose levels, elevated cholesterol levels in the participants studied $(\mathrm{P}>0.05)$.

\section{Conclusions}

The health fair model appears to be an effective method of surveillance and data collection of NCDs.

Non-communicable diseases (NCD) are the most common causes of death in St. Kitts. Four NCDs (cancer, heart disease, cerebrovascular disease, diabetes mellitus) accounted for more than $56 \%$ of all deaths in the period 2004-2013. ${ }^{1}$ These conditions also carry the highest healthrelated burden as well. Hypertension is recorded as the cause for $10-15 \%$ of hospital admissions; heart disease and diabetes, 5-10\%, respectively; stroke, $3-8 \%$; cancer, $1 \% .^{2}$ No change in the trend lines have been noted from 1999 to the present day. 3,4 The Federation of St. Christopher (St. Kitts) and Nevis is a two island state. There are two ministries of health with parallel organizational structures. Each island has a Minister and Permanent Secretary who are responsible for organizing and managing public health services. The
Ministry of Health on St. Kitts also has federal responsibilities, which include public health surveillance and disease prevention and control programs on both islands; reporting data; and creating national strategy. There is a single chief medical officer for the Federation who is responsible for oversight. The latest census data available (2011) showed the population to be 47,196: St. Kitts, 34,918; Nevis, 12,278. The country currently has a young population. However, the World Health Organization (WHO) reported statistics indicate that the crude birth rate and fertility rate remain below replacement level. St Kitts and Nevis also have had a high emigration rate that has caused its population to decline for many years.

Seventy- five percent (75\%) of the population of St Kitts 
and Nevis are of African descent. The next-largest ethnic group is Afro-European (12.3\%), followed by mulatto (5.3\%), East Indian and Afro-East Indian (5\%), South Asian ethnic groups (3\%) and other groups. Most inhabitants are descendants of West African slaves. ${ }^{5}$ The Federation is now classified as a high-income country (United States Dollars, USD 13,330 per capita income). Education to the $11^{\text {th }}$ grade is free at all levels. Literacy rates are high $(>95 \%)$. The healthcare system is divided into public and private sectors. Children under the age of 18 and persons over the age of 62 years are exempt from charges at public health facilities for basic health care; these essential services are not withheld for other groups due to inability to pay. ${ }^{6}$ However, the principal hospital and the health clinics are both underfunded and understaffed. The WHO has been advocating for regular standardized surveys of the health status of the populations of the member nations since the 21st World Health Assembly in 1968. To this end, WHO implemented the STEP Assessment tool. This tool consists of three parts: (i) Behavioral survey that assesses demographics, alcohol and tobacco consumption habits, diet, physical activity, and selfreported chronic health conditions; (ii) Physical Measurements of blood pressure and BMI; (iii) Biochemical measurements of fasting blood sugar, total cholesterol, urinary sodium and creatinine. Presumably these data permit the design and implementation of evidence based intervention programs to improve the health of the population. Further, repeating the survey offers objective proof of the outcome of the intended intervention.

The ministry of health for the Federation implemented the NCDs WHO STEPwise approach to Surveillance (STEPS) survey in 2007-8. St. Kitts alone was surveyed. Those responding to the questionnaire were distributed along sex and age ranges found on the island and were chosen at random. They represented $6.6 \%$ of the population of St. Kitts. Nevis was not surveyed. Biochemical testing of participants was not conducted. Findings were reported to WHO in $2008^{7}$ The survey has never been repeated. The International University of Nursing (IUON), a for-profit US nursing school in St. Kitts, conducted a short-term study of 372 women from industrial sites in 2009. They were followed over several months to ascertain whether interventions would affect changes in blood pressure, weight, random blood glucose and total cholesterol measurements. Changes noted were minimal. ${ }^{8}$ This is the only study reporting biochemical testing data. The global status report of the WHO (2010) presents results provided by the Ministry of Health. ${ }^{9}$ They differ substantially from those reported in the STEPwise survey of 2008 as well as the IUON study. No methodology was disclosed. Yet, additional reporting was made to WHO in 2018. ${ }^{10}$

The University of Medicine and Health Sciences (UMHS) is a for-profit US medical school whose basic science campus is located in St. Kitts. Approximately 300 students are in the first year class. The St. Kitts and Nevis chronic disease evaluation and management research group operates under the auspices of UMHS and in conformance with the institutional review board (IRB) of the Federation. Student volunteers, largely drawn from the second year class, were trained in data collection and point of care testing to expand and systematize data collection at community health fairs oper- ated in partnership with local non-profit organizations and religious groups. As data collection and reporting have been sporadic, largely incomplete, and conflicting on St. Kitts, the Research Group structured this pilot study to gather the data establishing the prevalence of non-communicable diseases on St. Kitts as well as to validate a community health fair model at various population centers as a means of surveying a representative portion of the population.

\section{METHODS}

Sites central to the bulk of the island population were selected. Health fairs were publicized. A shortened STEPwise questionnaire was administered to participants at entry. Anthropometric and biochemical screening data were provided to the participants; appropriate health counseling followed. This all followed the parameters previously approved by the IRB of the Federation. Written consent was obtained from all participants. Mortality data from 1999-2014 were collected from the Caribbean Public Health Agency. Cause of death is listed on the death certificate. Causes of death are coded to the conditions listed from the 10th revision of the International Statistical Classification of Diseases and Related Health problems (ICD-10) using the WHO rules and guidelines. ${ }^{5}$ Data reported in the STEPwise Non-Communicable Disease Risk Factor Survey ${ }^{7}$ was analyzed to establish baseline conditions. Compared as well were the IUON study ${ }^{8}$ and the 2010 and 2018 data reported to the $\mathrm{WHO}^{9,10}$ by the Ministry of Health.

The research group utilized the shortened STEPwise questionnaire for use at intake and expanded the anthropometric and biochemical screening of participants to include testing for macular degeneration (AMSLER) chart, blood pressure and pulse, BMI, percent body fat, peak expiratory flow rate (PEFR), hemoglobin, glucose, and total cholesterol. The shortened STEPwise questionnaire involved recording self-reported name, date of birth, age, gender, marital status, city of residence, hypertension (yes/no, (y/ $\mathrm{n})$ ), cholesterol $(\mathrm{y} / \mathrm{n})$, diabetes $(\mathrm{y} / \mathrm{n})$, cancer $(\mathrm{y} / \mathrm{n})$, other chronic disease $(y / n)$, smoking status $(y / n)$, and cigarette packs per day and years of use. The survey further gathered data on the number of times per weeks the participant consumed alcoholic beverages, exercised, ate meat, ate fried food, and ate meals prepared outside the home.

Blood pressures were taken manually in the left arm using the Tycos ${ }^{\circledR}$ sphygmomanometer Abnormally high pressures were rechecked by another observer. Height was measured with the participant standing against a wall to which a semi-rigid tape measure was affixed, while a flexible tape measure was used to record waist circumference with a cross-hand method. Weight was measured with a Thinner ${ }^{\circledR}$ ? bathroom scale, that had been verified accurate at 100 pounds known weight. PEFR was determined using a personal best Personal Best ${ }^{\circledR}$ peak flowmeter. CLIA waived testing devices were used to determine glucose, cholesterol, and hemoglobin (ACCU-ANSWER ISAW 4-IN-1 ${ }^{\circledR}$ as well as ACON MISSION ${ }^{\circledR}$ for hemoglobin).

With sufficient space available to assure privacy during its collection, urine was examined using dry chemistry methodology utilizing Life $_{2} 0{ }^{\circledR} 14$ test chemistry strips. Specific gravity, microalbumin, creatinine, calcium and biliru- 
bin were the parameters of interest. All data was coded onto Excel and analyzed using SPSS. ${ }^{\circledR}$ We performed a multivariate analysis on anthropometric and biochemical data broken down by age and sex, followed by stepwise regression to identify (any) independent variables. A $\mathrm{P}=0.05$ was chosen as a cutoff of significance. None were found. We report individual correlations below.

\section{HISTORICAL DATA (BASELINE REPORTS)}

\section{HYPERTENSION}

The 2007-8 STEPwise survey of St. Kitts in 2007-8 involved 1443 participants. Of those questioned, $14.8 \%$ of men and $24.3 \%$ of women self-reported a diagnosis of hypertension. For the 1081 participants in whom blood pressure determinations were made, $33.2 \%$ of men and $19.6 \%$ of women were hypertensive. Of those 178 taking antihypertensive medications, there was no report as to whether they were included in the group with measured hypertension ( $7.6 \%$ were men and $15.3 \%$ were women). However, a median pressure of $130 / 80 \mathrm{mmHg}$ was reported in the IUON study of 372 women. The mode was also $130 / 80 \mathrm{mmHg}$. It is not possible to extract the number of those with hypertension from that data set as reported. The latest data reported to WHO (2018) indicate a prevalence of hypertension at $28 \%$ for men, $24 \%$ for women. The number examined was not reported. This is a major change from the 2008 report to WHO.

\section{TACHYCARDIA}

Noted in the 2008 report to WHO was the observation that $2 \%$ of those surveyed had pulse rates $>100$ beats/minute.

\section{DIABETES MELLITUS}

In the 2007-8 STEPwise survey, $4.8 \%$ of men and $10.4 \%$ of women self-reported a diagnosis of diabetes mellitus. No data were reported to WHO in 2008. The median random glucose value reported in the IUON study was $98 \mathrm{mg} / \mathrm{dL}$ (or $5.4 \mathrm{mmol} / \mathrm{L}$ ) with a mode of $100 \mathrm{mg} / \mathrm{dL}$. It is not possible to extract the number of those with diabetes from that data set as reported. The latest data reported to WHO (2018) indicate a prevalence of $13 \%$ for men and $17 \%$ for women. Neither the number examined nor the methodology employed were reported.

\section{OBESITY}

As to obesity, the 2007-8 STEPs study records body mass in$\operatorname{dex}(\mathrm{BMI})>25 \mathrm{~kg} / \mathrm{m}^{2}$ in $32 \%$ of men and $49.4 \%$ of women. The IUON women's study in 2009 demonstrated a median BMI of $31 \mathrm{~kg} / \mathrm{m}^{2}$ and a mode of $30 \mathrm{~kg} / \mathrm{m}^{2}$. The percent body fat $>80$ as measured by waist to hip ratio was found in $72 \%$ of women surveyed. The median was $86 \%$ with a mode of $100 \%$. The latest data reported to the WHO (2018) state $15 \%$ of men and $31 \%$ of women as overweight. The number examined was not reported. This is a major change from the 2008 report to WHO and is incompatible with the IUON data. Neither the number examined nor the methodology employed were reported.

\section{CHOLESTEROL}

In the 2007-8 STEPwise survey, $6.5 \%$ of men and $11.1 \%$ of women of the 1398 participants responding self-reported a diagnosis of elevated cholesterol.

Of the participants in the IUON women's study, 22\% had an elevated cholesterol $(>200 \mathrm{mg} / \mathrm{dL}$ or $5.1 \mathrm{mmol} / \mathrm{L})$ The median was $174 \mathrm{mg} / \mathrm{dL}$ with a mode of $191 \mathrm{mg} / \mathrm{dL}$. The researchers conducting the IUON study reported, "the cholesterol levels were significantly less than expected in relation to calculated BMI [and waist/hip ratios]."8 There was little correlation between hypertension, elevated glucose levels, elevated cholesterol levels, and obesity in the IUON study $(\mathrm{r}=0.02)$. As with a small group intervention by the Ministry of Health in $2016,{ }^{11}$ the IUON study also demonstrated marginal improvements in objective measurements following education and training. Neither study lasted for more than a few weeks.

\section{RESULTS}

The pilot study was terminated early due to government ordered measures to prevent the entry or delay the propagation of Coronavirus disease 2019 (COVID-19) to the island nation. Urine collection was suspended and is not reported.

\section{DEMOGRAPHIC COMPARISON AND QUESTIONNAIRE EVALUATION}

Participants in this study were ambulatory and self-selected. Over the course of the pilot study, 155 individuals (88 women and 67 men) were assessed. This represents $0.44 \%$ of the population on St. Kitts.

\section{DEMOGRAPHIC COMPARISON}

Sixty-seven percent of Kittitians reside in 12 population centers around the island; Sixty-seven percent reside in Basseterre, St. Paul's, or St. Peter's parishes. ${ }^{12}$ Health fair participants were largely drawn from these areas $(\mathrm{r}=0.79)$. The percentage of men questioned in the 2007-8 Stepwise survey broken down by age and reported in deciles were 15.5\% (20-29),16.0\% (30-39),14.5\% (40-49),13.5\% (50-59), $6.5 \%$ (60-69) respectively; women, $15.0 \%, 15.3 \%$, $14.0 \%$, $14.2 \%$, and $8.0 \%$,respectively. Women constituted sixty-two percent of those surveyed. The age group 60-69 was underrepresented. ${ }^{7}$ In the IUON study the age breakdown was $27.9 \%$ (22-31), 31.3\% (32-41), 21.7\% (42-51), and $4.8 \%$ (52-67). As the study involved women in the workplace, younger women were over-represented. ${ }^{8}$

Health Fair participants were distributed as follows: Men, 9.3\% (20-29), 23.2\% (30-39), 18.6\% (40-49), 20.1\% (50-59), 16.3\% (60-69) respectively; women, $14.0 \%, 8.8 \%$, $17.5 \%, 26.3 \%, 14.0 \%$, respectively. Women constituted fiftyseven percent of those examined. The distribution of men and women in the age groups 30-60 years of age is comparable between the 2007-8 STEPwise survey and the Health Fair study (r=0.74 and 0.79 , respectively). 
Table 1. Lifestyle: Comparison between STEPs and UMHS Questionnaire results

\begin{tabular}{lllll} 
& \multicolumn{2}{l}{ 2007-8 STEPs } & & UMHS Pilot \\
\cline { 2 - 5 } & Men (\%) & Women (\%) & Men (\%) & Women (\%) \\
\hline Tobacco use & 16.1 & 1.1 & 15.0 & 2.3 \\
\hline Alcohol use $>$ 4 days/week & 45.129 .9 & 14.37 .8 & 44.814 .9 & 18.21 .1 \\
\hline No exercise & $39.3^{*}$ & 44.8 & 33.0 \\
\hline Meals away from home $>$ 2/week & $42.1^{*} 20.4^{*}$ & & $46.5^{*} 11.0^{*}$ & \\
\hline Meat consumption & $* *$ & $96^{*}$ & & \\
\hline Fried food consumption & $* *$ & & & \\
\hline
\end{tabular}

* No sex breakdown provided, ** No data provided, STEPs - World Health Organization (WHO) STEPwise approach to Surveillance, UMHS - University of Medicine and Health Sciences, St Kitts

Table 2. Self-reported past medical history comparison

\begin{tabular}{lllll}
\hline & \multicolumn{2}{c}{ 2007-8 STEPs } & UMHS Pilot & Women (\%) \\
\cline { 2 - 5 } & Men (\%) & Women (\%) & Men (\%) & 31.8 \\
\hline Hypertension & 14.8 & 24.3 & 29.9 & 20.4 \\
\hline Diabetes mellitus & 4.8 & 10.4 & 19.4 & 9.1 \\
\hline High cholesterol & 6.5 & 11.1 & 23.9 & 12.5 \\
\hline Cancer & $* *$ & & 3.0 & \\
\hline
\end{tabular}

** No data provided, STEPs - World Health Organization (WHO) STEPwise approach to Surveillance, UMHS - University of Medicine and Health Sciences, St Kitts

\section{QUESTIONNAIRE VALIDATION}

The 2007-8 STEPs survey reported $16.1 \%$ of men as current smokers; women, $1.1 \%$. The Health Fair sample reported $15.0 \%$ of men and $2.3 \%$ of women as current smokers. All the women self-reporting smoked a few cigarettes daily as did $57 \%$ of the men. The remainder smoked 1-2 packs of cigarettes daily. As to alcohol use, the 2007-8 Stepwise survey reported $45.1 \%$ of men and $14.3 \%$ of women as current drinkers. Those who consumed alcohol on at least four days in a week were reported as $29.9 \%$ for men and $7.8 \%$ for women. The Health Fair sample reported $45 \%$ of men and $18 \%$ of women as current drinkers; fewer consumed alcohol on at least four days in a week (14.9\% of men and $1.1 \%$ of women). The 2007-8 Stepwise survey did not report on the extent of consumption of meat and fried foods by Kittitians. Meat consumption was common and generally frequent among Health Fair participants. The Health Fair sample found $9.1 \%$ of women responding did not eat meat at all. Health Fair participants refrained from fried foods and harmful oils (men, 22.2\%; women, 38.6\%). Both the 2007-8 STEPwise survey and the Health Fair sample report that at least one-third of Kittitians do not consume fruit or vegetables daily. The 2007-8 Stepwise survey reported that $42.1 \%$ of respondents took 1-2 meals outside the house while $20.4 \%$ did so 3-5 times weekly. Men did so more frequently than women (2.0:1.4). The Health Fair participants took 1-2 meals outside the house $7.8 \%$ of the time while $3.9 \%$ did so 3-5 times weekly. Men did so more frequently than women
$(1.8: 1.0)$.

Low levels of physical activity in Kittitians was reported as $38.3 \%$ in the 2007-8 STEPwise survey. No breakdown by sex was provided. The Health Fair participants reported low levels of physical activity as well. As many as $44.8 \%$ of men and $33.0 \%$ of women self-reported no physical activity.Data distribution and trends were similar for men and for women in both studies for tobacco and alcohol consumption, as well as exercise $(\mathrm{r}=1, P<0.05)$. Heavy consumption of alcohol as well as consumption of meals outside the home were markedly less in 2019-2020 than in 2007-8. This is summarized in Table 1 . Self-reported diagnoses varied widely between 2007-8 and 2019-20. This is shown in Table 2.

\section{HYPERTENSION}

2007-8 STEPwise data show $14.8 \%$ of men and $24.3 \%$ of women to reporting a history of diagnosed hypertension. Upon measurement of the blood pressure, 33.2\% of men and $19.6 \%$ of women had SBP $>140 \mathrm{mmHg}$ or a DBP $>90$ $\mathrm{mmHg} ; 8.6 \%$ of men and $7 \%$ of women had SBP $>160 \mathrm{mmHg}$ or a DBP $>100 \mathrm{mmHg}$. UMHS Health Fair screening identified $26.9 \%$ of men and $39.8 \%$ of women participants reporting a diagnosis of hypertension. One of those was on medication. However, $30.7 \%$ of men and $28.2 \%$ of women participants were found to have an SBP $>140 \mathrm{mmHg}$ or a DBP $>90$ mmHg. ${ }^{13}$ One participant with systolic hypertension alone was profoundly anemic ( $\mathrm{Hb} 6.4 \mathrm{mg} / \mathrm{dL})$. An additional $8.8 \%$ were noted to be pre-hypertensive. There were seven par- 
ticipants with hypertension or pre-hypertension who were also obese. There was no correlation between hypertension and obesity $(\mathrm{r}=0.11)$. Of the participants who were hypertensive, $13.6 \%$ were not aware of this previously.

\section{TACHYCARDIA}

A heart rate $>100$ beats per minute in the absence of anemia, volume depletion, fever, or anxiety, is inappropriate. ${ }^{14}$ UMHS Health Fair screening found 5 participants to have inappropriate tachycardia. Determination of thyroid hormone levels was not part of the pilot study.

\section{DIABETES MELLITUS}

Although the 2007-8 STEPwise survey had $4.8 \%$ of men and $10.4 \%$ of women reporting a diagnosis of diabetes, no data as to prevalence were reported to the WHO. In 2018 a prevalence of diabetes in $13 \%$ of men and $17 \%$ in women was reported to the WHO. No information was provided as to how these data were derived. UMHS Health Fair screening identified $19.4 \%$ of men and $20.5 \%$ of women self- reporting a diagnosis of diabetes. UMHS Health Fair biochemical screening identified 8 of 139 (5.7\%) participants as having an elevated glucose that met WHO/ADA accepted criteria for diagnosis of diabetes mellitus on a random blood glucose determination (>200 mg/dL or $11.1 \mathrm{mmol} / \mathrm{L}) .{ }^{15}$ Only one participant with an elevated random glucose also had a BMI $>30 \mathrm{~kg} / \mathrm{m}^{2}(\mathrm{r}=0.15, P>0.05)$. No participant with an elevated random glucose had an elevated cholesterol $(\mathrm{r}=0.08$, $P>0.05$ ). There were an additional $8.6 \%$ of participants with a random blood glucose level $>120 \mathrm{mg} / \mathrm{dl}(6.66 \mathrm{mmol} / \mathrm{L})$ but $<200 \mathrm{mg} / \mathrm{dl}(11.1 \mathrm{mmol} / \mathrm{L})$, drawn more than 2 hours after their last meal, who were not previously diagnosed as prediabetic or diabetic. Follow-up is needed to establish a diagnosis in these participants.

\section{OBESITY}

UMHS Health Fair screening data demonstrated 33.3\% of men and $31.9 \%$ of women of the 101 who participated in screening to be overweight; $12.1 \%$ of men and $18.0 \%$ of women to be obese utilizing BMI criteria of $>30 \mathrm{~kg} / \mathrm{m}^{16}$ and height/waist ratio of $>0.5 .^{12}$ Height to waist ratio did not uncover occult cases of obesity as determined by BMI cutoffs although it is reputed to be a better reflection of abnormal metabolism than is the BMI. The IUON study (2009) found more than $50 \%$ of women to be overweight and $72 \%$ to have excess body fat. Both the IUON study and the current Health Fair sample identify obesity in a larger percentage of Kittitians than was reported to the WHO (2018).

\section{CHOLESTEROL}

The 2007-8 STEPwise survey reported a previous diagnosis of elevated cholesterol in $6.5 \%$ of men and $11.0 \%$ of women. The UMHS Health Fair identified 23.9\% of men and 9.1\% of women self-reporting a diagnosis of elevated cholesterol. UMHS Health Fair biochemical screening data demonstrated $48.1 \%$ of 54 participants to have an elevated cholesterol: $46.7 \%$ were women while $61.5 \%$ were men. A cholesterol level $>200 \mathrm{mg} / \mathrm{dL}(5.2 \mathrm{mmol} / \mathrm{L})$ was reported as high. ${ }^{17}$ of those with elevated cholesterols, $37.5 \%$ were not previously aware of this. Only one participant with an elevated cholesterol level also had a BMI $>30 \mathrm{~kg} / \mathrm{m}^{2}$. ( $\left.\mathrm{r}=-0.07, P>0.05\right)$. No participant with an elevated cholesterol level also had an elevated random glucose level $(\mathrm{r}=0.09, P>0.05)$. There was no correlation between blood glucose or cholesterol levels or obesity. ( $\mathrm{r}=0.08, P>0.05)$. The IUON study found $22 \%$ of women to have an elevated cholesterol. The Health Fair population sample is more diverse and older than that of IUON. However, when viewed with the obesity/body fat determinations in the IUON study, it also appears there is little correlation between obesity and an elevated cholesterol level in Kittians.

\section{HEMOGLOBIN}

UMHS Health Fair screening data demonstrated $25 \%$ of 72 participants to be anemic; $23.1 \%$ were men and $40.6 \%$ were women. We employed a cut-off value of $12 \mathrm{~g} / \mathrm{dL}$ as a determination of anemia. ${ }^{18}$ of those patients with anemia, $38.8 \%$, equally divided between men and women, had hemoglobin levels below $10 \mathrm{~g} / \mathrm{dL}$ (and as low as $6.4 \mathrm{mg} / \mathrm{dL}$ ). Neither screening for occult blood loss nor hemoglobinopathy was part of the pilot study.

\section{PEFR}

UMHS Health Fair screening data demonstrated $34.7 \%$ of 49 evaluable participants to have increased airway resistance. PEFR screening as a surrogate for $\mathrm{FEV}_{1}$ was employed because of high concordance. ${ }^{19}$ GOLD criteria were employed. ${ }^{20}$

\section{MACULAR DEGENERATION SCREEN (AMSLER)}

UMHS Health Fair screening data demonstrated 3 participants to have abnormal AMSLER screens. The data are summarized in Table 3 .

\section{DISCUSSION}

There were four reasons for conducting this pilot study. First, the lack of objective data on the health status of the island nation. There are significant unexplained differences between official reports from the Ministry of Health to WHO from 2008, 2010, and 2018, regarding the prevalence of chronic non-communicable disease on the island. Further, data from the Ministry of Health is also at variance with the only study examining biochemical data, that of IUON in 2009. The challenges of a STEPwise survey in many poorer nations has been related to the: "high turnover of personnel involved in surveillance; the lack of resources available at the country level to support surveillance activities; out-of-date sampling frames; lack of geographical accessibility of some areas in some countries; weak infrastructure (e.g., travel and transport systems) that makes household surveys difficult; weak country capacity in data management, analysis, and report writing; and technological problems with step-3 measurements, to name but a few. In a number of countries, these limitations have resulted in poor data quality." 21 The pilot study provides biochemical 
Table 3. Comparison of objective biometric data

\begin{tabular}{|c|c|c|c|c|}
\hline & \multicolumn{2}{|c|}{ 2007-8 STEPs } & \multicolumn{2}{|c|}{ UMHS Pilot } \\
\hline & Men (\%) & Women (\%) & Men (\%) & Women (\%) \\
\hline \multicolumn{5}{|l|}{ Blood pressure } \\
\hline $120 / 80-139 / 89 \mathrm{mmHg}>$ & $* *$ & ** & 40.3 & 43.6 \\
\hline $140 / 90$ & 33.2 & 19.6 & 30.6 & 28.2 \\
\hline \multicolumn{5}{|l|}{ Heart rate } \\
\hline$>100 / \mathrm{bpm}$ & 2.3 & 1.5 & 6.5 & 5.7 \\
\hline \multicolumn{5}{|l|}{ BMI } \\
\hline$<25.0 \mathrm{~kg} / \mathrm{m}^{2}$ & 28.8 & 16.9 & 39.2 & 21.3 \\
\hline 25.0-29.9 & 36.2 & 30.6 & 33.3 & 31.9 \\
\hline $30.0-34.9$ & 35.0 & 52.5 & 21.6 & 46.9 \\
\hline$>35.0$ & & & 5.8 & 17.1 \\
\hline Cholesterol & ** & & & \\
\hline$>200 \mathrm{mg} / \mathrm{dl}$ & & & 46.7 & 61.5 \\
\hline Random blood sugar & ** & & & \\
\hline $126-189 \mathrm{mg} / \mathrm{dl}$ with $>8$ hour since last meal & & & 3.7 & 3.7 \\
\hline$>200$ & & & 3.6 & 3.7 \\
\hline Hemoglobin & $* *$ & & & \\
\hline$<12.0 \mathrm{~g} / \mathrm{dl}$ & & & 23.1 & 40.6 \\
\hline PEFR & $* *$ & & & \\
\hline$>80 \%$ of predicted & & & $34.7^{*}$ & \\
\hline AMSLER positive & $* *$ & & 4.4 & 8.7 \\
\hline
\end{tabular}

* No sex breakdown provided, *** No data provided, AMSLER - macular degeneration, STEPs - World Health Organization (WHO) STEPwise approach to Surveillance, UMHS - University of Medicine and Health Sciences, St Kitts

confirmation of non-communicable disease states in a representative portion of the island population. This has not been available previously.

Second, to examine whether self-reported diagnoses could be confirmed. The pilot study demonstrates that selfreported diagnoses are not reliable and could not be confirmed with biochemical testing. Medical records were not available to confirm self-reported diagnoses. Third, to validate a shorter, less-time consuming questionnaire for identifying risk factors for non-communicable diseases. Fourth, to demonstrate the feasibility of surveying a representative portion of the nation through the use of healthcare volunteers in training at community health fairs at various population centers.

The pilot study validates the shortened questionnaire for determination of risk as well as the feasibility of the community health fair model to survey a representative portion of the population. The pilot study identified other potentially treated health problems not anticipated by the WHO (anemia, obstructive lung disease, and macular degeneration). The pilot study also raises questions as to the value of measuring cholesterol levels as in this representative group of participants no correlation between obesity, elevated glucose, and elevated cholesterol levels could be demonstrated $(\mathrm{P}>0.05)$; in the IUON sample that conclusion may be drawn as well.

While WHO is interested in quantifying sodium excre- tion in the surveyed population, there are significant problems with interpretation of that data. The most recent systematic review and meta-analysis of randomized trials to address the flaws in previous studies relied upon to advance the salt hypothesis has shown that the magnitude of blood pressure lowering achieved with sodium reduction showed a dose-response relation, was small, and was greater for older populations, non-white populations, and those with higher blood pressure. Short term studies underestimate the effect of sodium reduction on blood pressure. Fractional urine samples can produce overestimates of sodium intake when true intake is low but underestimates when true intake is high. ${ }^{22}$ As with determination of fat intake, diet analysis may be a better alternative.

There are no good data available for anemia in the West Indies. Further, the number of patients with severe anemia suggests the need to screen for Sickle Cell disease and other hemoglobinopathy. There is no good inexpensive mass screening tool for the detection of treatable non-cataract vision loss. A positive AMSLER screen identifies those at risk for macular degeneration. However, it may miss up to $50 \%$ of those with early disease. In a large systematic review, $20 \%$ of those patients with a positive screening test were confirmed to have disease requiring intervention. ${ }^{23}$ Early identification of macular degeneration can lead to treatment to forestall blindness. Risk factors are hypertension, obesity, and tobacco use. They are cumulative with 
age. The "dry" form is the most common, seen in $90 \%$ of cases, and may be slowed with an antioxidant vitamin preparation.

The use of point of care testing with provision of the results to participants appears to be sufficient incentive to encourage participation. Additional incentives are yet to be attempted to maximize participation, point of care testing itself is expensive. Glucose and hemoglobin levels at the time of a patient encounter may permit timely intervention. That is not generally the case with other analytes. A blood draw for analysis at a central laboratory would be cost-effective. Future urine dipstick screening may provide further incentive as a more pertinent and less expensive determination of renal and liver dysfunction as well as to detect the microalbuminuria associated with small vessel damage due to diabetes mellitus. ${ }^{24}$ The use of a pocket-sized ultrasound instrument to screen for cardiac disease, lung disease, abdominal organ abnormality, and peripheral vascular disease could be incorporated with biochemical screening as it is highly accurate even in the hands of non-experts, reproducible, quantifiable, and offers structural data that are only indirectly identified through biochemical screening. ${ }^{25}$ The community health care model suggests that trained volunteers using low cost equipment can effectively collect data and can also identify other health problems not anticipated by the WHO. And serve as an important strategy to be implemented across other low-income nations. That is now being explored.
Acknowledgements: We acknowledge the assistance of Dr. Peter E. Lee, Associate Professor, Behavioral Science, UMHS, who provided the statistical software and reviewed the study.

Funding: UMHS.

Authorship contributions: KA structured the study. $\mathrm{AB}$ organized and directed the health fairs. The others, medical students, ran the health fairs, collected the data, evaluated the data, performed a literature search, and prepared a preliminary report. KA prepared the final report that was reviewed and approved by all participants.

Competing interests: The authors completed the Unified Competing Interest Form at www.icmje.org/coi-diclosure.pdf (available upon request from the corresponding author) and declare no competing interests.

\section{Correspondence to:}

Kenneth Alonso

St. Kitts and Nevis Chronic Disease Evaluation and Management Research Group

University of Medicine and Health Science

Basseterre, St. Kitts

West Indies

kalonso@umhs-sk.net 


\section{REFERENCES}

1. Eldememire-Shearer D, James K, Morris C, et al. Chronic disease and ageing in the Caribbean: Opportunities knock at the door. West Indian Med J. 2011;60(4):471-477.

2. Avery G, Sanmugathas N, Khan M, et al. Is there a case for the early introduction of HPV vaccine for cervical cancer in St. St. Kitts and Nevis? Poster presented at the: 2013 CARPHA/CHRC 58th Annual Conference; Barbados.

3. Hospedales CJ, Samuels TA, Cummings R, et al. Raising the priority of chronic noncommunicable diseases in the Caribbean. Rev Panam Salud Publica. 2011;30(4):393-400. https://iris.paho.org/handle/106 $\underline{65.2 / 9507 .}$

4. Razzaghi H, Martin DN, Quesnel-Crooks S, et al. 10 -year trends in noncommunicable disease mortality in the Caribbean region. Rev Panam Salud Publica. 2019;43:e37. doi:10.26633/rpsp.2019.37

5. World Population Review. 2020. https://worldpopul ationreview.com/countries/saint-kitts-and-nevis-pop ulation/. Accessed March 20, 2020.

6. Pan American Health Organization. Saint Kitts and Nevis. Health in the Americas; 2017. https://www.pah o.org/salud-en-las-americas-2017/?p=4298. Accessed March 20, 2020.

7. St. Kitts and Nevis STEPwise Approach to noncommunicable disease risk factor survey, 2007-8. 2008. http://ghdx.healthdata.org/geography/saint-kit ts-and-nevis/. Accessed March 20, 2020.

8. McLane S. Changing the Health of a Nation: A multiphase health promotion community. Presented at the: 8th Cardiovascular Nursing and Nurse Practitioners Meeting; 2016; Las Vegas, Nevada.

9. World Health Organization. Global Status Report on Non-Communicable Diseases. Geneva, Switzerland: World Health Organization; 2010. http s://www.who.int/nmh/publications/ncd_report2010/e n/. Accessed March 20, 2020.

10. World Health Organization. Non-Communicable Diseases: Country Profiles. Geneva, Switzerland: World Health Organization; 2018. https://www.who.i nt/publications-detail/9789241514620.
11. Changing the treatment approach to NCDs is another first for St. Kitts And Nevis. The St Kitts Nevis Observer. https://www.thestkittsnevisobserve r.com/changing-the-treatment-approach-to-ncds-isanother-first-for-st-kitts-and-nevis/. Published September 6, 2016. Accessed March 20, 2020.

12. Yoo E-G. Waist-to-height ratio as a screening tool for obesity and cardiometabolic risk. Korean J Pediatr. 2016;59(11):425. doi:10.3345/kjp.2016.59.11.425

13. Whelton PK, Carey RM, Aronow WS, et al. 2017 ACC/AHA/AAPA/ABC/ACPM/AGS/APhA/ASH/ASPC/ NMA/PCNA. Guideline for the prevention, detection, evaluation, and management of high blood pressure in adults: a report of the American College of Cardiology/American Heart Association task force on clinical practice guidelines. J Am Coll Cardiol. 2018;71(19):e127-e248. doi:10.1016/j.jacc.2017.11.00 $\underline{6}$

14. Shen WK. How to manage patients with inappropriate sinus tachycardia. Heart Rhythm. 2005;2(9):1016-1019. doi:10.1016/j.hrthm.2005.05.00 $\underline{2}$

15. American Diabetes Association. Standards of Medical Care in Diabetes - 2020. Dia Care. 2020;43(Supplement 1):S14-S31. doi:10.2337/dc20-s0 $\underline{02}$

16. CDC. Defining Adult Overweight And Obesity. 2020. https://www.cdc.gov/obesity/adult/defining.ht $\underline{\mathrm{ml}}$.

17. Grundy SM, Stone NJ, Bailey AL, et al. 2018 AHA/ ACC/AACVPR/AAPA/ABC/ACPM/ADA/AGS/APhA/ ASPC/NLA/PCNA Guideline on the management of blood cholesterol: A report of the American College of Cardiology/American Heart Association task force on clinical practice guidelines. Circulation. 2019;139(25). doi:10.1161/cir.0000000000000625

18. World Health Organization. Haemoglobin Concentrations for the Diagnosis of Anaemia and Assessment of Severity. Vitamin and Mineral Nutrition Information System. Geneva, Switzerland: World Health Organization; 2011. http://www.who.in t/vmnis/indicators/haemoglobin.pdf. Accessed March 20, 2020

19. Mahboub B, Alzaabi A, Soriano JB, et al. Casefinding of chronic obstructive pulmonary disease with questionnaire, peak flow measurements and spirometry: A cross-sectional study. BMC Res Notes. 2014;7(1):241. doi:10.1186/1756-0500-7-241 
20. Rabe KF, Hurd S, Anzueto A, et al. Global strategy for the diagnosis, management, and prevention of chronic obstructive pulmonary disease: GOLD executive summary. Am J Respir Crit Care Med. 2007;176(6):532-555. doi:10.1164/rccm.200703-456so

21. Riley L, Guthold R, Cowan M, et al. The World Health Organization STEPwise Approach to Noncommunicable Disease Risk-Factor Surveillance: Methods, Challenges, and Opportunities. Am J Public Health. 2016;106(1):74-78. doi:10.2105/ajph.2015.302 $\underline{962}$

22. Huang L, Trieu K, Yoshimura S, et al. Effect of dose and duration of reduction in dietary sodium on blood pressure levels: Systematic review and metaanalysis of randomised trials. BMJ. 2020;368:m315. $\underline{\mathrm{d}}$ oi:10.1136/bmi.m315
23. Faes L, Bodmer NS, Bachmann LM, Thiel MA, Schmid MK. Diagnostic accuracy of the Amsler grid and the preferential hyperacuity perimetry in the screening of patients with age-related macular degeneration: Systematic review and meta-analysis. Eye. 2014;28(7):788-796. doi:10.1038/eye.2014.104

24. Glauser J, Montgomery A. Urine protein as a rapid screen for renal function in the ED: Can it replace serum creatinine in selected patients? Emerg Radiol. 2004;10(6):319-322. https://pubmed.ncbi.nlm.nih.go v/15278715/.

25. Galusko V, Bodger O, Ionescu A. A systematic review of pocket-sized imaging devices: Small and mighty? Echo Res Pract. 2018;5(4):113-138. doi:10.15 30/erp-18-0030 